\title{
Rossby wave dynamics of the North Pacific extra-tropical response to El Niño: importance of the basic state in coupled GCMs
}

\author{
Andrew Dawson • Adrian J. Matthews • \\ David P. Stevens
}

Received: 21 December 2009/ Accepted: 15 May 2010

(C) Springer-Verlag 2010

\begin{abstract}
The extra-tropical response to El Niño in a "low" horizontal resolution coupled climate model, typical of the Intergovernmental Panel on Climate Change fourth assessment report simulations, is shown to have serious systematic errors. A high resolution configuration of the same model has a much improved response that is similar to observations. The errors in the low resolution model are traced to an incorrect representation of the atmospheric teleconnection mechanism that controls the extra-tropical sea surface temperatures (SSTs) during El Niño. This is due to an unrealistic atmospheric mean state, which changes the propagation characteristics of Rossby waves. These erroneous upper tropospheric circulation anomalies then induce erroneous surface circulation features over the North Pacific. The associated surface wind speed and direction errors create erroneous surface flux and upwelling anomalies which finally lead to the incorrect extra-tropical SST response to El Niño in the low resolution model. This highlights the sensitivity of the climate response to a single link in a chain of complex climatic processes. The correct representation of these processes in the high resolution model indicates the importance of horizontal resolution in resolving such processes.
\end{abstract}

Keywords Rossby wave dynamics - North Pacific . Extra-tropical SST · El Niño · GCM · Basic state

A. Dawson $(\square)$. A. J. Matthews · D. P. Stevens

School of Mathematics, University of East Anglia, Norwich, UK

e-mail: andrew.dawson@uea.ac.uk

A. J. Matthews

School of Environmental Sciences, University of East Anglia,

Norwich, UK

\section{Introduction}

The current state-of-the-art in coupled climate modelling is represented by the models used for the Intergovernmental Panel on Climate Change (IPCC) fourth assessment report (AR4); (Randall et al. 2007). These models have typical resolutions of $2^{\circ}$ in the atmosphere and $1^{\circ}-2^{\circ}$ in the ocean. Many coupled models of typical AR4 resolution suffer from systematic errors in simulating mean climate and its variability. The double inter-tropical convergence zone (ITCZ) problem (Mechoso et al. 1995), where a persistent ITCZ south of the equator in the eastern and central equatorial Pacific is produced in addition to the observed ITCZ north of the equator, is common in AR4 models. This systematic error in simulating the mean climate in the tropical Pacific affects the location of the Walker circulation and the simulation of El Niño. Many AR4 models have an equatorial Pacific cold tongue that is too equatorially confined and extends too far into the western tropical Pacific. This implies an unrealistic simulation of coupled heat transfer mechanisms, such as tropical instability waves (TIWs), in the tropics.

Increased horizontal resolution in coupled climate models has historically improved the accuracy of climate simulations (e.g., Gordon et al. 2000; Pope and Stratton 2002; Johns et al. 2006). There is a growing body of evidence to show that resolving processes on scales as small as the oceanic mesoscale in coupled climate models can improve their ability to realistically represent large-scale mean climate and its variability. Roberts et al. (2004) found that increasing the ocean resolution of the UK Met. Office coupled general circulation model (GCM) in its HadCM3 configuration to $\frac{1}{3}^{\circ}$ resulted in many improvements in the simulation of oceanic circulation. Shaffrey et al. (2009) showed that the coupled GCM HiGEM1.2, 
with high horizontal resolution in both the atmosphere $\left(\sim 1^{\circ}\right)$ and the ocean $\left(\frac{1}{3}^{\circ}\right)$, allows ocean-atmosphere coupling to occur on these small spatial scales. In particular the interactions between the atmosphere and TIWs in the Pacific Ocean is realistically captured in the high resolution version, compared to the lower resolution configuration (HadGEM1.2; $\sim 2^{\circ}$ atmosphere, $1-^{\circ} \frac{1}{3}^{\circ}$ ocean). Roberts et al. (2009) showed that resolving these TIWs in the Pacific Ocean can result in a reduced equatorial cold tongue bias. This corresponds to a more realistic oceanic mean state, which implies an improved atmospheric mean state. Shaffrey et al. (2009) also noted that the split ITCZ problem is reduced in HiGEM1.2 compared with that in HadGEM1.2, a model of typical AR4 resolution.

El Niño is one of the major modes of global climate variability. For coupled models to be used for both long and short term climate prediction, they must be able to accurately represent El Niño. An accurate representation of El Niño not only requires realistic tropical SST anomalies, but also an accurate representation of the extra-tropical SST response, as extra-tropical SSTs are also important in the climate system, with SST gradients influencing the location of mid-latitude storm tracks (Norris 2000; Inatsu et al. 2002; Brayshaw et al. 2008). Deser and Blackmon (1995) used empirical orthogonal function (EOF) analysis of observed winter SST anomalies to understand North Pacific El Niño teleconnections. Their EOF 1 pattern is a canonical representation of the spatial distribution of El Niño SST anomalies in both the tropical Pacific and the extra-tropical North Pacific.

Tropical SST anomalies during El Niño lead to convection anomalies in the tropics. These convection anomalies lead to anomalous divergence and associated anomalous vorticity in the upper troposphere. These vorticity anomalies drive atmospheric Rossby waves that affect global atmospheric circulation. These large-scale atmospheric teleconnections alter the surface energy balance in the extra-tropics, largely due to surface wind speed anomalies affecting sensible and latent heat fluxes (Deser and Blackmon 1995), but changes in near surface temperature, humidity, and cloud distribution also have a role to play (Alexander et al. 2002). The atmosphere acts as a bridge spanning from the tropical Pacific to the extratropical North Pacific, hence this teleconnection mechanism is often referred to as the atmospheric bridge.

Most AR4 models have an inaccurate representation of the meridional extent of El Niño SST anomalies in the eastern tropical Pacific, and produce SST anomalies that extend too far to the west (Randall et al. 2007). Another common problem in AR4 models is the inability to accurately simulate the temporal variation of SSTs during El Niño, with variability generally occurring on time scales faster than observed (AchutaRao and Sperber 2002).
Navarra et al. (2008) found that increased atmosphere resolution alone was unable to eliminate the systematic westward shift of El Niño SST anomalies in coupled models. However, it has been shown that high resolution in the atmosphere component of a coupled model can improve the representation of El Niño, in particular the temporal SST variability in the tropics (Guilyardi et al. 2004; Navarra et al. 2008). Shaffrey et al. (2009) found that the simulation of tropical El Niño SST anomalies is improved in integrations of HiGEM1.2. The ability of HiGEM1.2 to simulate TIWs improves the representation of mean climate, which in turn improves the simulation of El Niño.

In this paper we will conduct a detailed examination of the differences in the global simulation of El Niño between the low resolution model HadGEM1.2 and the high resolution model HiGEM1.2. We will build on the preliminary findings of Shaffrey et al. (2009), which focused on the core tropical variability of El Niño, while we focus particularly on the physical mechanisms involved in the extra-tropical response to El Niño. The HiGEM1.2 and HadGEM1.2 models are very similar in parameterization and configuration; their only difference is the horizontal resolution and accompanying changes to certain model parameters such as subgrid-scale mixing that need to be made to ensure stability. The overall aim is to determine the improvement that can be made by moving to higher horizontal resolution. This not only means determining if the performance of the high resolution model is better or worse than the low resolution model, but also understanding the reasons for any performance differences. Coupled modelling is computationally expensive and increases in horizontal resolution compete for computational resources with other model improvements, such as increasing the vertical resolution or addition of further "physics" elements. Hence, it is important that resolution should not be increased without understanding where and why it is needed.

This paper is organized as follows: Sect. 2 describes the model configurations, data sets, and analysis methods used. Section 3 describes results from analysing SST variability in the tropical and extra-tropical North Pacific. Section 4 describes the atmospheric response to El Niño SST anomalies. Section 5 describes the surface energy balance during El Niño. Section 6 contains an analysis of the atmospheric background state in relation to Rossby wave propagation. Section 7 contains an analysis of Rossby wave generation, and Sect. 8 provides a summary and conclusions from this work.

\section{Data and methods}

Two coupled climate models are used to examine the effect of horizontal resolution on the simulation of El Niño. The 
high resolution coupled model is HiGEM1.2 (Shaffrey et al. 2009). In HiGEM1.2 the horizontal resolution is $\frac{1}{3}^{\circ} \times$ $\frac{1}{3}^{\circ}$ globally in the ocean and $0.83^{\circ}$ latitude $\times 1.25^{\circ}$ longitude in the atmosphere. The low resolution model is HadGEM1.2, which is very similar to HadGEM1 (Johns et al. 2006). In HadGEM1.2 the horizontal resolution is $1^{\circ} \times 1^{\circ}$ (increasing to $\frac{1}{3}^{\circ}$ meridionally near the equator) in the ocean and $1.25^{\circ}$ latitude $\times 1.875^{\circ}$ longitude in the atmosphere. This horizontal resolution is typical of stateof-the-art coupled climate models. The physics and parameterizations are largely the same in HiGEM1.2 and HadGEM1.2, allowing for a relatively clean comparison between model resolutions. The major differences are in the ocean component, where high horizontal resolution has necessitated modifications to the subgrid-scale mixing parameterizations (Shaffrey et al. 2009).

Two observational data sets are used in this study. Gridded sea surface temperature (SST) data is from the UK Meteorological Office HadISST1.1 data set (Rayner et al. 2003). All other gridded fields are from the National Centers for Environmental Prediction/National Center for Atmospheric Research (NCEP/NCAR) reanalysis project (Kalnay et al. 1996).

For this study all data fields are first averaged into individual November to March (NDJFM) seasonal means. This reflects the tendency for the effects of El Niño to be more pronounced during boreal winter (Philander 1990). The length of the season is chosen so as to capture not only El Niño anomalies in the tropics, but also the extra-tropical response produced by teleconnections from the tropics. A sampling period of 50 NDJFM seasons is used throughout this study. All anomalies are relative to the full 50 year NDJFM mean. The size of this sampling period is constrained by the amount of reliable observed SST data available (1957/58 to 2006/07 inclusive). Both models experience a significant adjustment period during the first 20 years of integration. This period is removed and the following 50 years are used for this analysis.

Empirical orthogonal function (EOF) analysis is used to examine SST variability. In this paper, EOF 1 is presented as the correlation of the principal component (PC) time series associated with EOF 1 and the data time series at each grid point. This is a measure of the spatial localization of the co-varying part between the NDJFM Pacific SST anomaly and its primary mode of temporal variability, in effect showing the areas in which the observed or modelled SST varies in the same way as the pattern of EOF 1 . Correlations that pass the $95 \%$ significance level are not hatched, correlations that do not pass the $95 \%$ significance level are marked with hatching. Significance is determined by a Student's $t$ test using the Fisher $Z$ transformation (Wilks 2006). The critical correlation coefficient for $N=50$ degrees of freedom is $r_{*}=0.278$.
Regression maps are used throughout this study (Kiladis and Weickmann 1992). The index used for all regression maps is an area average of SST in the region $178^{\circ} \mathrm{W}-106^{\circ} \mathrm{W}$, $6^{\circ} \mathrm{S}-6^{\circ} \mathrm{N}$. This area captures the core variability of El Niño. This index will be referred to as the Equatorial Pacific (EP) index from here on. Regression maps represent the anomaly in response to a $1^{\circ} \mathrm{C}$ change in the EP SST index.

\section{North Pacific sea surface temperature component of El Niño}

The leading EOF (EOF 1) of observed NDJFM Pacific SST anomaly (Fig. 1a) shows statistically significant warm anomalies in the eastern equatorial Pacific cold tongue, and corresponding cool anomalies in the western Pacific warm pool. This describes the eastward movement of the Pacific warm pool during El Niño. The EOF 1 pattern is very similar to EOF 1 of Deser and Blackmon (1995), suggesting that EOF 1 is a good representation of the spatial distribution of El Niño SST anomalies. The PC associated with EOF 1 is highly correlated with the EP index $(r=0.97)$. PC 1 is also highly correlated with the NINO3 index $(r=0.94)$. The NINO3 index (Trenberth 1997) is a time series of SST averaged over the region $5^{\circ} \mathrm{N}-5^{\circ} \mathrm{S}$ and $150^{\circ}-90^{\circ} \mathrm{W}$ and is representative of the core SST variability in the eastern equatorial cold tongue during El Niño. Hence PC 1 is accurately capturing the temporal variability of El Niño.

The EOF 1 structures in both HiGEM1.2 and HadGEM1.2 (Fig. 1 b, c) have significant tropical correlations similar to those of the observations. However, the equatorial warm anomalies extend considerably further westward across the Pacific Ocean than is observed. This pattern of extended warming is common in coupled climate models (Randall et al. 2007). The core differences between the high and low resolution models are in the extra-tropical component of El Niño. This component of El Niño is characterized in the observed data set by warm SST anomalies along the coast of North America and south of Japan, and cool SST anomalies in the central North Pacific.

In HiGEM1.2 there are significant warm anomalies along the coast of North America, and significant cool anomalies in the central North Pacific, consistent with observations, although the correlations are slightly weaker. However, the Western North Pacific region is simulated poorly by HiGEM1.2 with negligible correlations there compared with those of above 0.4 in the observations.

HadGEM1.2 exhibits a very different extra-tropical pattern. There are very few areas of significant correlation in the North Pacific compared with observations. There is a significant warm anomaly in the central Pacific at $150^{\circ} \mathrm{W}$, $43^{\circ} \mathrm{N}$ in an area that should show a cool anomaly, and there is no significant anomaly along the North American 


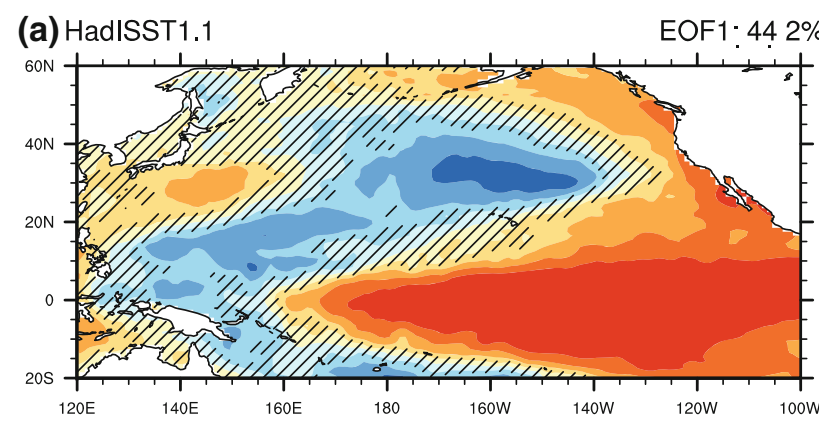

$\begin{array}{ll}\text { (b) HiGEM1.2 EOF1: } 32.9 \% & \end{array}$

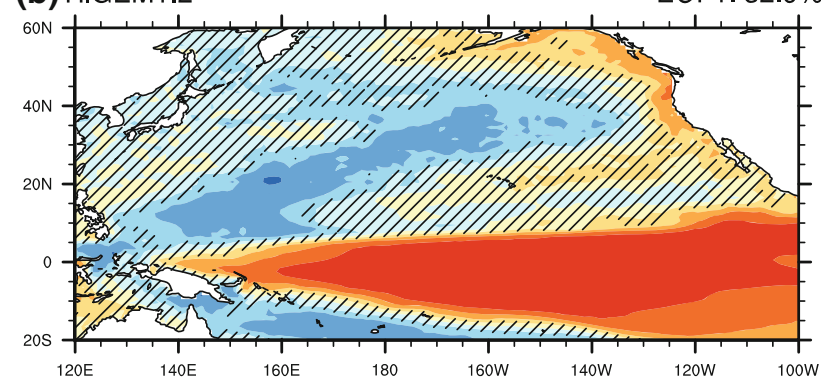

$\begin{array}{ll}\text { (c) HadGEM1.2 } & \text { EOF1: } 29.0 \%\end{array}$

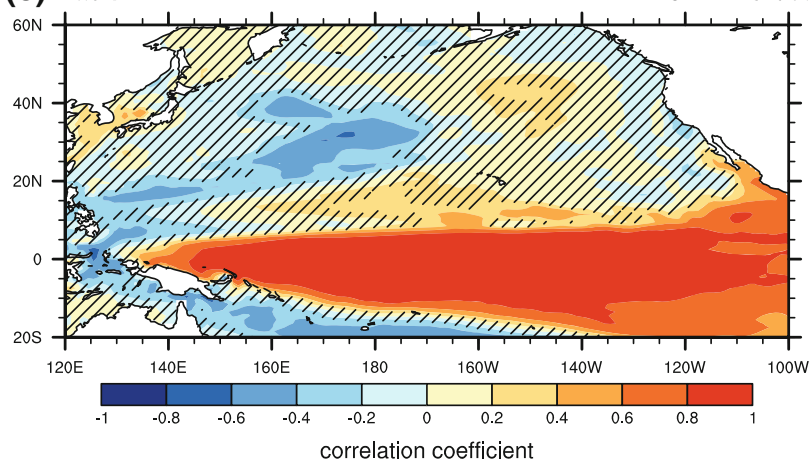

Fig. 1 EOF 1 of northern winter (NDJFM) Pacific SST anomaly normalized by correlation. Correlations that pass the $95 \%$ significance level are not hatched, correlations that do not pass the $95 \%$ significance level are hatched. Contour interval is 0.2. a HadISST1.1, b HiGEM1.2, c HadGEM1.2

coast. There are few significant warm anomalies around the South-East Asian coast. However, like HiGEM1.2, HadGEM1.2 simulates this region rather poorly in general.

\section{Atmospheric response to El Niño}

The reason for these differences in the extra-tropical response to El Niño in the observations and the two models is now examined, using the framework of the atmospheric bridge discussed in Sect. 1.

\subsection{Tropical atmospheric forcing during El Niño}

During El Niño the Pacific warm pool moves eastward, driving anomalous convection in the central tropical (a) NCEP/NCAR Reanalysis

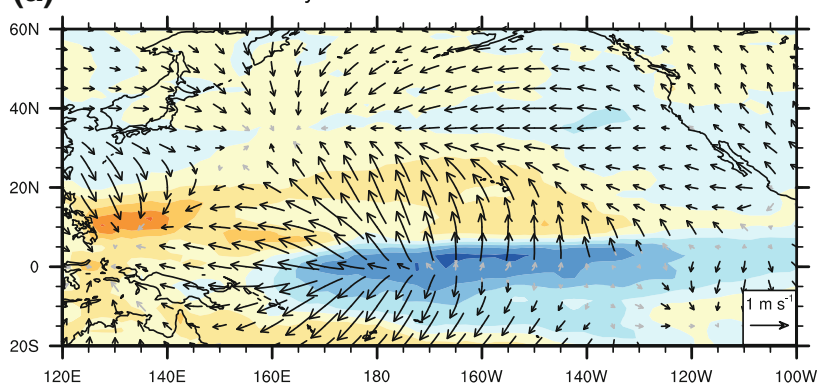

(b) HiGEM1.2

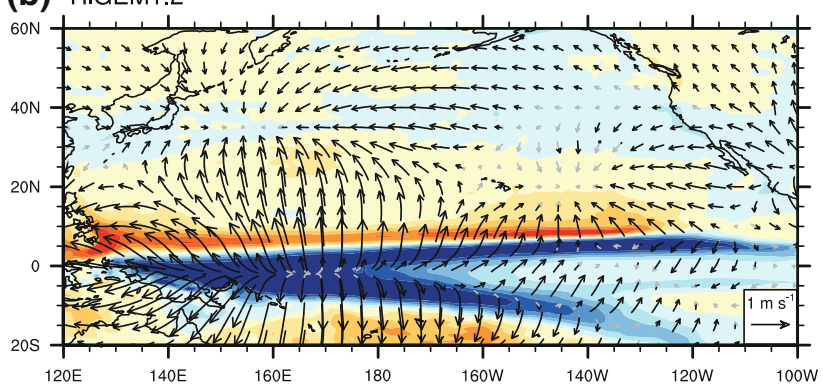

(c) HadGEM1.2

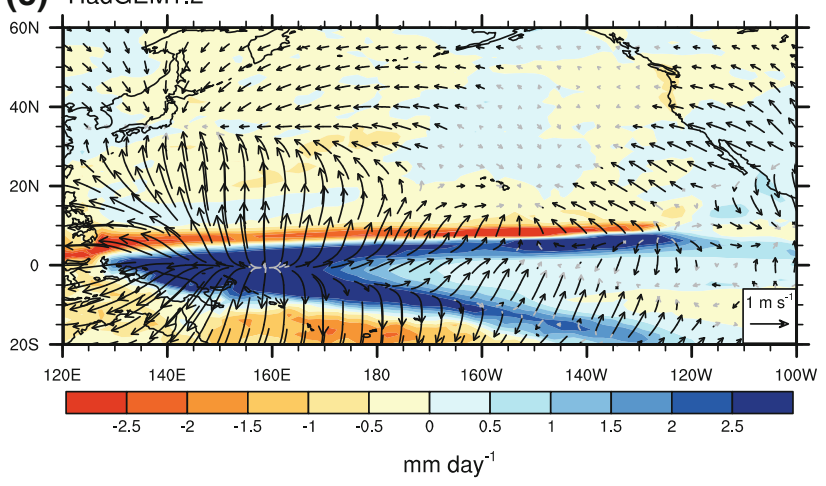

Fig. 2 Northern winter (NDJFM) precipitation rate (colours, mm day $^{-1}$ ) and $200 \mathrm{hPa}$ divergent wind (arrows, $\mathrm{m} \mathrm{s}^{-1}$ ) anomaly patterns associated with a $1{ }^{\circ} \mathrm{C}$ departure of the EP index. Divergent wind arrows for regressions that pass the $95 \%$ significance level are coloured black, arrows for regressions that do not pass the $95 \%$ significance level are coloured grey. Contour interval is $0.5 \mathrm{~mm} \mathrm{day}^{-1}$. a NCEP/NCAR Reanalysis, b HiGEM1.2, c HadGEM1.2

Pacific. The latent heat release in this anomalous convection then forces an upper tropospheric response. Here, surface precipitation rate is used as a measure of this vertically integrated latent heat release. This relationship is valid provided that horizontal advection of cloud particles between their formation and arrival at the surface is negligible, which is a reasonable assumption for the large spatial scales considered here.

Regression maps of NDJFM precipitation and $200 \mathrm{hPa}$ divergent wind are shown in Fig. 2. The largest observed precipitation rate anomalies are in the central tropical Pacific, consistent with an El Niño. The precipitation 
anomaly patterns produced in both models are distinctly different to observations, with the largest anomalies situated in the western tropical Pacific. This is likely due to the greater westward extent of the tropical SST anomalies in both HadGEM1.2 and HiGEM1.2. There are slight differences between the precipitation anomaly patterns in HiGEM1.2 and HadGEM1.2. HiGEM1.2 has less of a split ITCZ. This is because the cold tongue error is not as pronounced in HiGEM1.2 as it is in HadGEM1.2 (Shaffrey et al. 2009).

The main centre of anomalous $200 \mathrm{hPa}$ divergence in the observations and both models is over the large precipitation anomaly in the tropics. Hence, in areas where large amounts of latent heat are being released, there is large-scale ascent throughout the troposphere, consistent with the tropical atmospheric dynamics discussed above. Regression maps of $500 \mathrm{hPa}$ vertical velocity for observations and each model (not shown) are very similar in the tropics to their precipitation rate counterparts in Fig. 2.

There is a difference in the longitude of the tropical heating between HiGEM1.2 and HadGEM1.2, of the order of $5-10^{\circ}$. This change in longitude is small when compared to the total longitudinal extent of the tropical heating, which is around $40^{\circ}$. The shift in the longitude of tropical heating between HiGEM1.2 and HadGEM1.2 is small when compared to the difference in the longitude of heating between observations and the models, which is of the order of $25^{\circ}$. As we will show, the extra-tropical response to El Niño in HiGEM1.2 is very similar to the observed response even though tropical heating is shifted approximately $25^{\circ} \mathrm{W}$ from observations to HiGEM1.2. This suggests that the relatively small intra-model difference in heating longitude is not likely to be a major factor in the performance differences between HiGEM1.2 and HadGEM1.2.

Figure 2 provides a clear illustration of the initial stages of the atmospheric bridge. Latent heat is released in the tropics, air ascends, and there is divergence in the upper troposphere. It is clear that HiGEM1.2 and HadGEM1.2 have different patterns of anomalous precipitation and divergence to the observed atmosphere. However, the initial part of the atmospheric bridge (tropical heating and upper tropospheric forcing) appears to be similar in the high and low resolution models.

This result suggests that the differences in extra-tropical response to El Niño between HiGEM1.2 and HadGEM1.2 cannot be explained simply in terms of inadequate surface forcing for the atmospheric bridge. Although there may be some subtle, yet significant differences in surface forcing, it is also likely that the HadGEM1.2 atmosphere is behaving quite differently to that of HiGEM1.2 in order to produce its extra-tropical response.
4.2 Upper atmospheric circulation response to El Niño

Regression maps of $200 \mathrm{hPa}$ stream function anomaly for NDJFM for reanalysis data, high resolution, and low resolution coupled models are shown in Fig. 3. These show the upper level circulation anomalies associated with El Niño. The observations (Fig. 3a) show a deepened Aleutian low (negative, cyclonic stream function anomaly) over the

(a) NCEP/NCAR Reanalysis

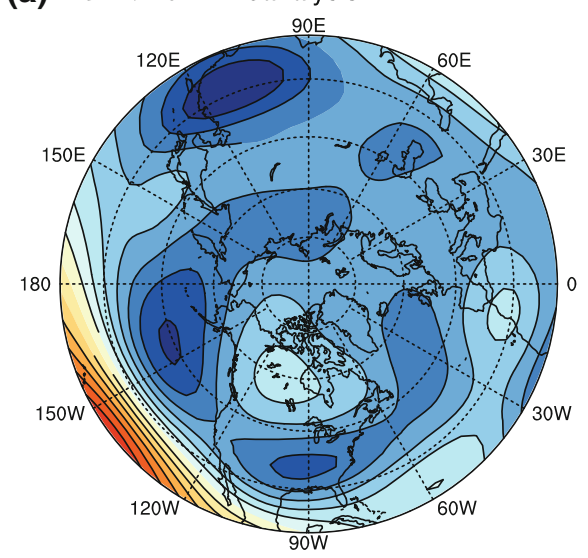

(b) HiGEM1.2

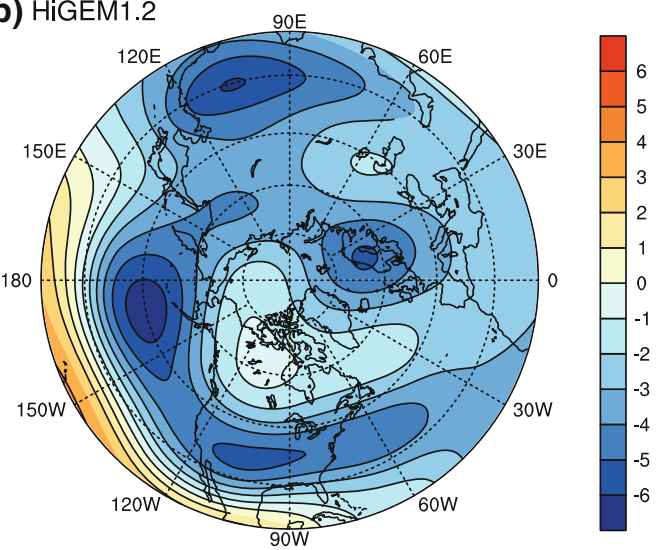

(c)

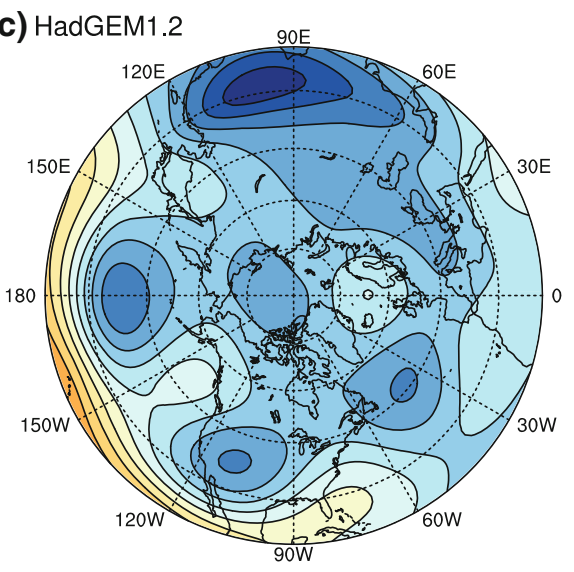

$10^{6} \mathrm{~m}^{2} \mathrm{~s}^{-1}$

Fig. 3 Northern winter (NDJFM) $200 \mathrm{hPa}$ stream function anomaly associated with a $1{ }^{\circ} \mathrm{C}$ departure of the EP index. Contour interval is $10^{6} \mathrm{~m}^{2} \mathrm{~s}^{-1}$. a NCEP/NCAR reanalysis, b HiGEM1.2, c HadGEM1.2 
North Pacific, this is part of a wave train that originates in the Pacific and extends across Canada (anticyclonic) and into the North Atlantic (cyclonic). This anomalous wave train is excited by vorticity anomalies in the upper troposphere induced by anomalous divergence over regions of strong anomalous convection (Sardeshmukh and Hoskins 1988). The wave train has a zonal wavenumber of approximately $4-5$.

The extra-tropical circulation structure in HiGEM1.2 is similar to that in the observations over the Pacific-North American (PNA) region. The wave train is somewhat different when it reaches the Atlantic; the anticyclonic anomaly over Canada extends into the mid-Atlantic, and the cyclonic anomaly is shifted eastward to Scandinavia.

The stream function anomalies associated with El Niño in HadGEM1.2 have a very different pattern to, and are generally weaker than those in HiGEM1.2 and observations. The negative stream function anomaly over the North Pacific is slightly westward, at the date line, compared to that in HiGEM1.2 and observations. The downstream wave train then shows a much more separated structure that is quite unlike the pattern seen in both the observations and HiGEM1.2.

Hence, the upper level circulation anomalies significantly deviate from observed behaviour in HadGEM1.2. This suggests that atmospheric Rossby waves that are excited in the upper troposphere are generated and/or propagate differently in HadGEM1.2 than in HiGEM1.2 and observations. This will be investigated further in Sects. 6 and 7. Before determining the cause of the difference between the high and low resolution models it is worthwhile to show that these upper level circulation anomalies do indeed affect the surface in the extra-tropics, and to understand how these surface anomalies can explain the different extra-tropical SST anomalies seen in HadGEM1.2.

\subsection{Surface atmospheric circulation response to El Niño}

Figure 4 shows regression maps of extra-tropical North Pacific surface wind anomalies overlaid on SST anomalies for observations, HiGEM1.2, and HadGEM1.2. The sense of the circulation corresponds well to the $200 \mathrm{hPa}$ stream function anomalies above (Fig. 3), consistent with the upper tropospheric potential vorticity anomalies inducing a surface circulation through an equivalent barotropic vertical structure (Hoskins et al. 1985). The surface wind anomalies in HadGEM1.2 are considerably weaker than those in HiGEM1.2, having about half the magnitude. This suggests that any SST response due to this anomalous surface wind may also be weaker. (a) HadISST1.1 \& NCEP/NCAR Reanalysis

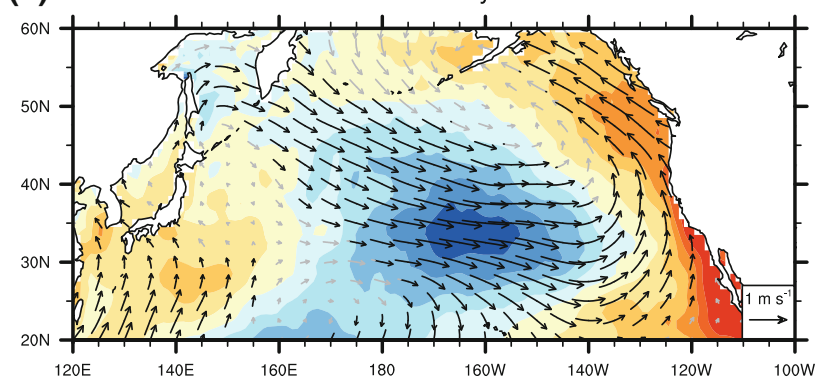

(b) HiGEM1.2

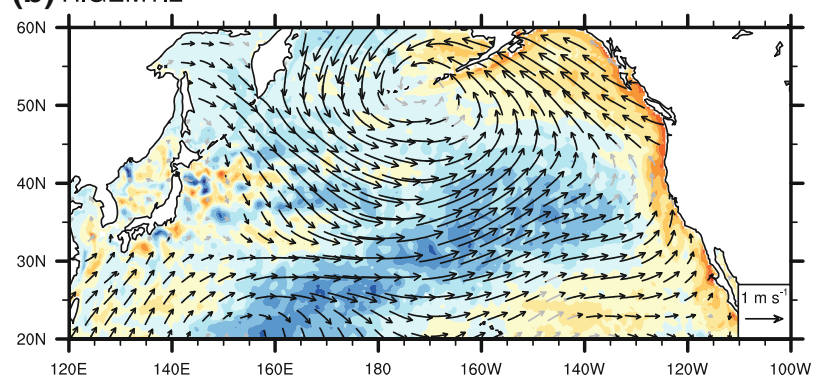

(c) HadGEM1.2

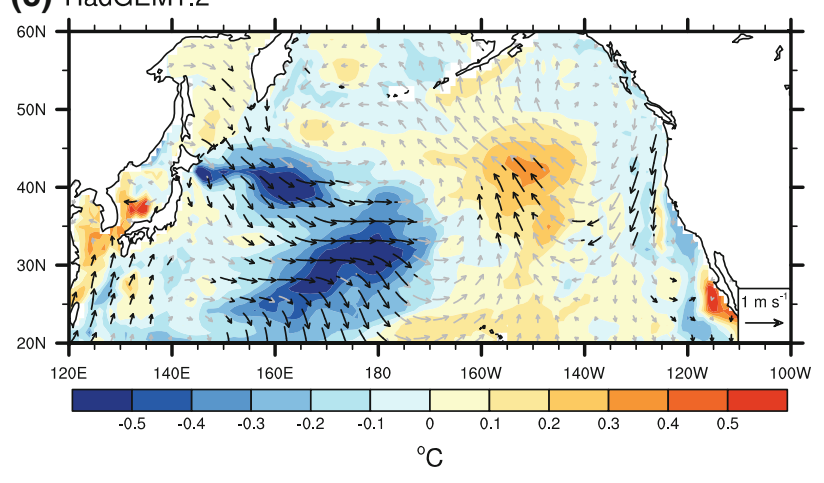

Fig. 4 Northern winter (NDJFM) anomalous SST (colours, ${ }^{\circ} \mathrm{C}$ ) and surface wind (arrows, $\mathrm{m} \mathrm{s}^{-1}$ ) regression maps associated with a $1^{\circ} \mathrm{C}$ departure of the EP index. Contour interval is $0.1^{\circ} \mathrm{C}$. Surface wind arrows for regressions that pass the $95 \%$ significance level are coloured black, arrows for regressions that do not pass the $95 \%$ significance level are coloured grey. a HadISST1.1 and NCEP/NCAR reanalysis, b HiGEM1.2, c HadGEM1.2

\section{Surface energy balance}

Previous studies (e.g., Luksch and von Storch 1992; Alexander 1992; Deser and Blackmon 1995; Alexander et al. 2002) have shown that the extra-tropical SST response to El Niño is controlled by alterations to surface heat fluxes caused by anomalous surface circulation. In order to understand how surface heat fluxes control the extra-tropical SST response to El Niño, the total net upward heat flux $Q_{T}$ is separated into its components:

$Q_{T}=Q_{\mathrm{SW}}+Q_{\mathrm{LW}}+Q_{S}+Q_{L}$,

where $Q_{\mathrm{SW}}$ is the flux of shortwave (solar) radiation, $Q_{\mathrm{LW}}$ is the flux of longwave (terrestrial) radiation, $Q_{S}$ is the 
sensible (turbulent) heat flux, and $Q_{L}$ is the surface latent (evaporative) heat flux. All fluxes are defined as positive upwards from the ocean to the atmosphere.

Figure 5 shows the sensible heat flux $\left(Q_{S}\right)$ and surface latent heat flux $\left(Q_{L}\right)$ components of the total heat flux anomaly associated with El Niño for observations, HiGEM1.2, and HadGEM1.2. A positive (negative) anomaly corresponds to a cooling (warming) of the ocean (note the reversed colour scale). Longwave $\left(Q_{\mathrm{LW}}\right)$ and shortwave $\left(Q_{\mathrm{Sw}}\right)$ flux anomalies (not shown) make a negligible contribution to the total heat flux anomaly in observations and both models. In observations and HiGEM1.2, the heat flux anomalies are consistent with SST anomalies in the extratropics. Heat flux anomalies in HadGEM1.2 are generally consistent with SST anomalies. However, HadGEM1.2 has a weak heat flux anomaly response along the North American coast. The sign of this anomaly implies a warm SST anomaly yet HadGEM1.2 lacks a significant warm SST anomaly in this region (Figs. 1, 4).

Understanding exactly how surface circulation anomalies affect surface heat fluxes requires these fluxes to be studied in more detail. The sensible heat flux $Q_{S}$ measures the amount of heat transferred between the atmosphere and ocean due to conduction and convection through turbulent eddies. The bulk aerodynamic formula for sensible heat flux is

$Q_{S}=\rho_{a} c_{p} c_{H} V\left(T_{s}-T_{a}\left(z_{r}\right)\right)$,

where $\rho_{a}$ is the density of air, $c_{p}$ is the specific heat capacity for dry air at a constant pressure, $c_{H}$ is the (a) NCEP/NCAR Reanalysis

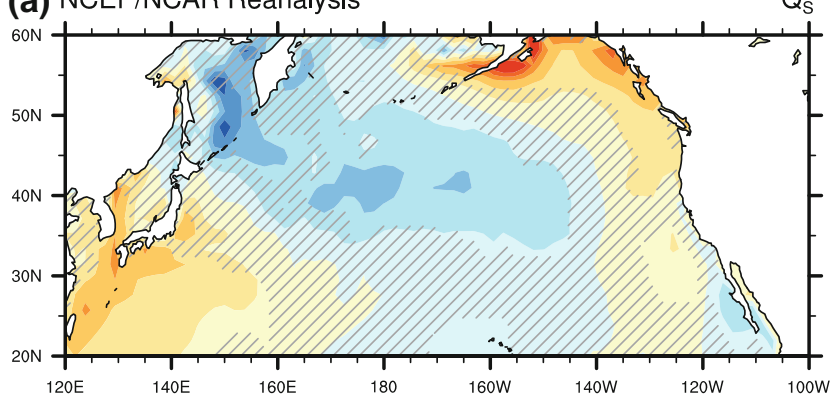

(c) HiGEM1.2

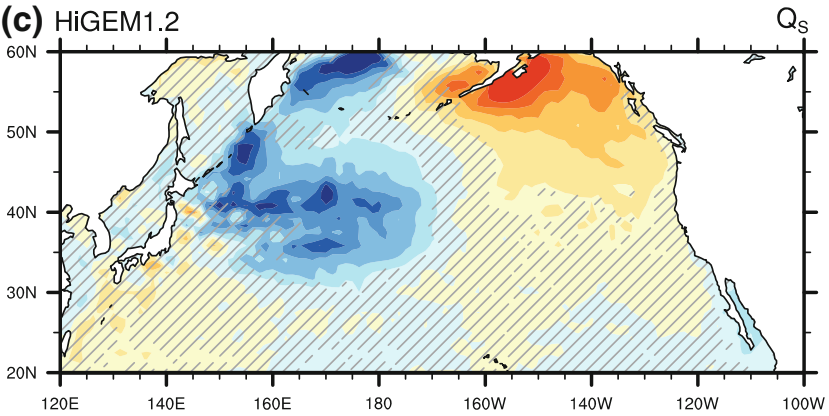

(e) HadGEM1. 2

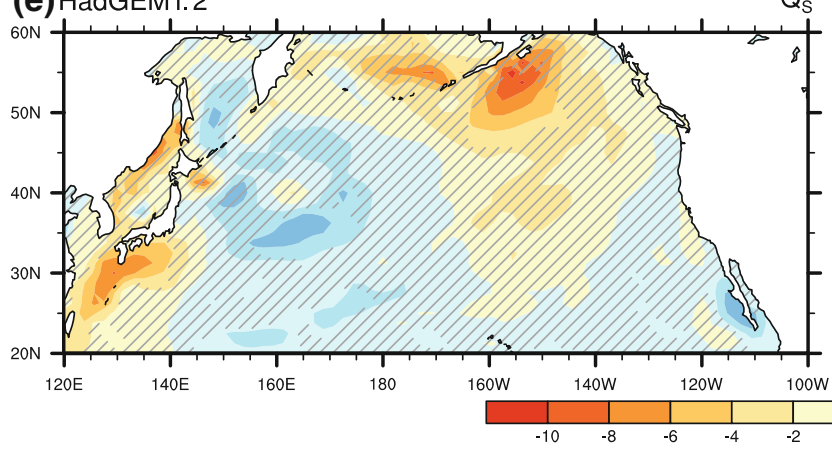

(b) NCEP/NCAR Reanalysis

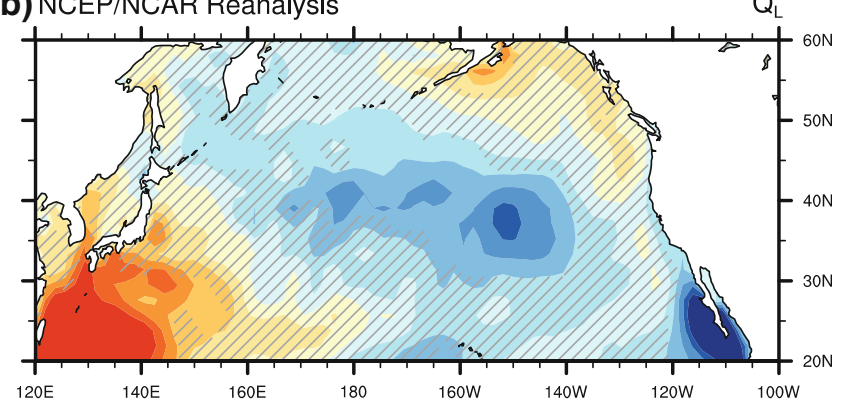

(d) HiGEM1.2

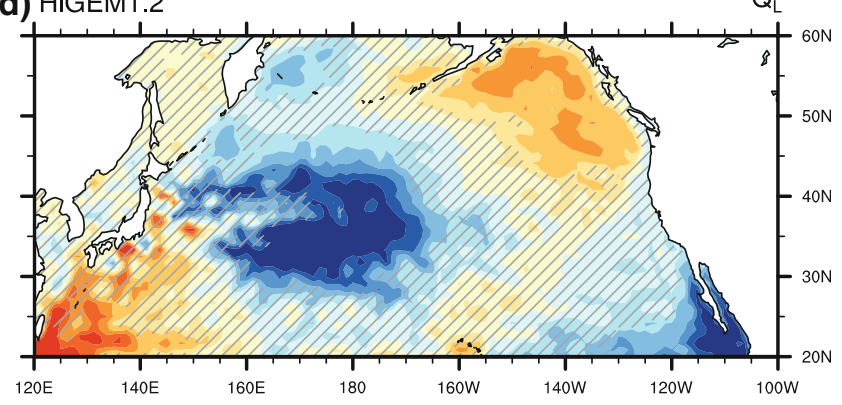

(f) HadGEM1.2

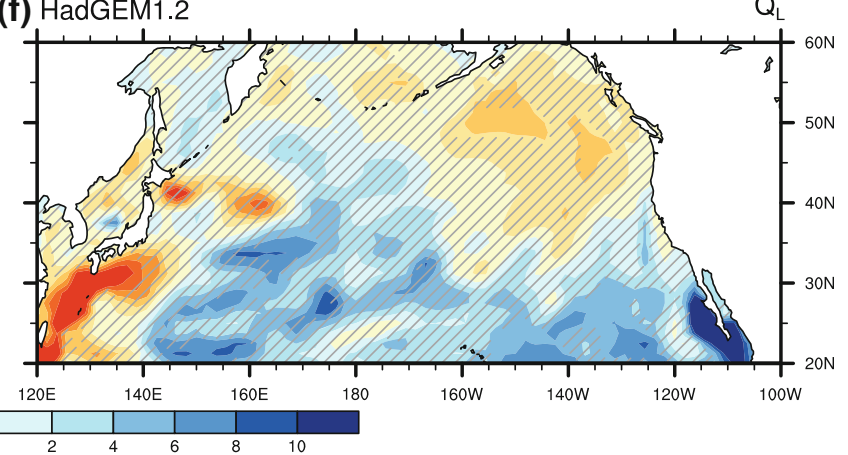

$W m^{-2}$

Fig. 5 Northern winter (NDJFM) heat flux anomaly regression maps associated with a $1{ }^{\circ} \mathrm{C}$ departure of the EP index for observations a sensible heat flux $\left(Q_{S}\right)$, b surface latent heat flux $\left(Q_{L}\right)$. Positive (negative) anomalies correspond to cooling (warming) of the ocean. c, d same as a, b but for HiGEM1.2. e, f same as a, b but for HadGEM1.2. Regressions that pass the $95 \%$ significance level are not hatched, regressions that do not pass the $95 \%$ significance level are hatched. Contour interval is $2 \mathrm{~W} \mathrm{~m}^{-2}$ 

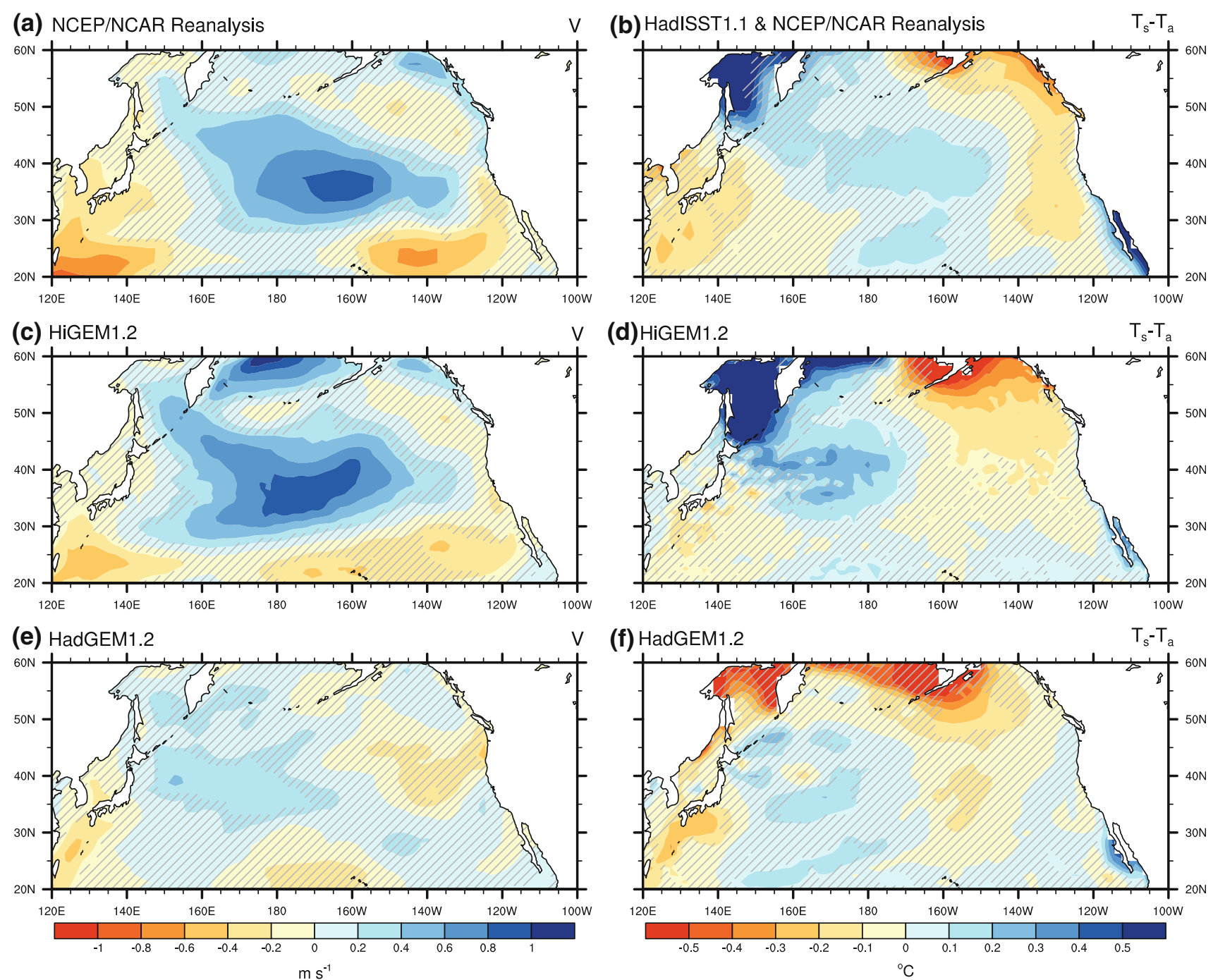

Fig. 6 Regression maps of northern winter (NDJFM) a total wind speed anomaly and $\mathbf{b}$ the anomalous difference between SST and $2 \mathrm{~m}$ air temperature, for observations (HadISST1.1 and NCEP/NCAR Reanalysis). Anomalies correspond to a $1^{\circ} \mathrm{C}$ departure of the EP index. $\mathbf{c}, \mathbf{d}$ same as $\mathbf{a}, \mathbf{b}$ but for HiGEM1.2. e, $\mathbf{f}$ same as $\mathbf{a}, \mathbf{b}$ but for

aerodynamic transfer coefficient for temperature, $V$ is the wind speed at the reference height $z_{r}, T_{s}$ is the sea surface temperature, and $T_{a}$ is the air temperature at the reference height $z_{r}$. The North Pacific winter sea surface temperature is higher than the air temperature, $T_{s}-T_{a}\left(z_{r}\right)>0$, and the sensible heat flux is positive (upwards), with the ocean losing energy to the atmosphere. The variable components of $Q_{S}$ are the wind speed and the difference between air and sea temperature, usually with changes in wind speed mainly determining sensible heat flux anomalies. Similarly, the bulk aerodynamic formula for latent heat flux also depends on total wind speed, and the specific humidity difference between the reference height, $z_{r}$, and the sea surface.
HadGEM1.2. Regressions that pass the $95 \%$ significance level are not hatched, regressions that do not pass the $95 \%$ significance level are hatched. Contour intervals are $0.2 \mathrm{~m} \mathrm{~s}^{-1}$ and $0.1^{\circ} \mathrm{C}$ for total wind speed and temperature difference respectively

Panels on the left side of Fig. 6 show the $10 \mathrm{~m}$ total wind speed anomaly associated with El Niño; positive (negative) anomalies correspond to increased (decreased) wind speed (note the reversed colour scale). In general, wind speed anomalies are consistent with the hypothesis that wind speed modulation of sensible and latent heat fluxes controls the extra-tropical North Pacific SST response to El Niño, with increased wind speed over cool SST anomalies and decreased wind speed over warm SST anomalies in the observations and both models. However, this relationship does not hold in the region along the North American coast north of $40^{\circ} \mathrm{N}$. In observations and HiGEM1.2, the total wind speed anomaly in this region is positive. This implies positive (upward) heat flux 
anomalies and cool SST anomalies, yet there are downward heat flux anomalies and the underlying SST anomalies are warm. HadGEM1.2 shows negative total wind speed anomalies along the North American coast implying negative (downward) heat flux anomalies and warm SST anomalies. However, even though there are downward heat flux anomalies, there are no significant warm SST anomalies.

Panels on the right side of Fig. 6 show regression maps of the difference $T_{s}-T_{a}\left(z_{r}\right)$ for $z_{r}=2 \mathrm{~m}$ (note the reversed colour scale). There is a negative anomaly in the sea-air temperature difference in the North American coastal region in observations and HiGEM1.2. This leads to the negative (downward) heat flux anomalies and warm SST anomalies. The reason for the reduction in the sea-air temperature difference can be traced to the direction of the anomalous surface winds. The anomalous surface winds along the North American coast are predominantly from the south in observations and HiGEM1.2. This implies they will advect warmer air from over warmer SSTs northward. Hence, the direction of the anomalous wind can be as important as the magnitude in controlling the surface energy balance. A similar argument explains the negative (downward) latent heat flux anomalies along the North American coast. The warm air advected northward by the southerly wind anomalies in the observations and HiGEM1.2 will also have a higher humidity. Hence the sea-air specific humidity difference will be reduced, decreasing evaporation and leading to the negative (downward) latent heat flux anomalies.

To fully understand the mechanisms of the extra-tropical response in HadGEM1.2 we must understand why the weak downward (heat into the ocean) heat flux anomaly along the North American coast does not produce significant warm SST anomalies. There must be another heat transport process acting in HadGEM1.2 that counteracts the heat flux anomaly.

Note that the anomalous poleward winds (Fig. 4) in observations and HiGEM1.2 will suppress upwelling along the North American coast. This is not the case in HadGEM1.2, where the equatorward wind anomalies are favourable to upwelling. A time series of this coastal upwelling is calculated from the vertical velocity at $50 \mathrm{~m}$ depth, averaged over the closed region bounded by the coast and the section from $149^{\circ} \mathrm{W}, 60^{\circ} \mathrm{N}$ to $124^{\circ} \mathrm{W}, 40^{\circ} \mathrm{N}$. This time series was then regressed onto the EP SST index to produce a single value that can be interpreted as the anomalous volume flux $\left(\mathrm{m}^{3} \mathrm{~s}^{-1}\right)$ into the coastal region associated with El Niño. A negative (positive) value indicates suppressed (enhanced) upwelling, and implied temperature increase (decrease) in the surface waters.

In HiGEM1.2 the anomalous volume flux associated with El Niño is negative $\left(-3.2 \times 10^{5} \mathrm{~m}^{3} \mathrm{~s}^{-1}\right)$ indicating that upwelling is suppressed. This is as expected given the surface wind and SST anomalies. This finding is complimentary to the result of the surface heat flux analysis, suggesting that along with advection of warm air, suppressed upwelling is a contributing factor to the presence of the warm SST anomaly along the North American coast in HiGEM1.2. However, in HadGEM1.2 the anomalous volume flux is positive $\left(0.5 \times 10^{5} \mathrm{~m}^{3} \mathrm{~s}^{-1}\right)$. The implication of this is that more cool water is upwelled into the upper layer of the ocean. Hence, there is an opposing flux of heat out of the surface waters which counteracts the anomalous heat input by the surface heat fluxes. This could explain the lack of a statistically significant warm anomaly along the North American coast in HadGEM1.2 (Fig. 1c).

We have shown that a realistic extra-tropical SST response to El Niño is dependent on accurate surface circulation anomalies. However, this process is not as simple as wind speed controlling the surface energy balance. The wind direction is critically important, as advection of warm humid air from the south affects the surface energy balance, and coastal upwelling is affected by anomalous wind direction. HiGEM1.2 has a realistic response only because the complex series of events leading to the surface wind anomalies occurs correctly. HadGEM1.2 performs relatively poorly as some processes in this series of events are poorly represented. The dynamics of the atmospheric bridge that links the tropical El Niño to its extra-tropical response are examined in the next section.

\section{Stationary Rossby wave propagation}

The upper tropospheric anomalies associated with El Niño in HadGEM1.2 are quantitatively and qualitatively different to those in HiGEM1.2 and the observed atmosphere (Sect. 4.2). These differences in circulation anomalies are then responsible for significant differences in the extra-tropical SST component of El Niño between the observations and models. In this section, the mechanisms responsible for the differences in the circulation anomalies are investigated.

The behaviour of these anomalies is governed by Rossby wave dynamics; planetary-scale waves that propagate westward relative to the time-mean background flow. The propagation paths of Rossby waves are therefore dependent on the basic state of the atmosphere. Given that HadGEM1.2 has very different upper troposphere stream function anomalies than the observations (Fig. 3), it is likely that the basic state of the HadGEM1.2 atmosphere is also significantly different in order to influence Rossby wave propagation to such an extent.

Figure 7 shows time-mean zonal wind for observations, HiGEM1.2 and HadGEM1.2 in the Pacific sector. The basic state in HiGEM1.2 is similar to that in observations, 


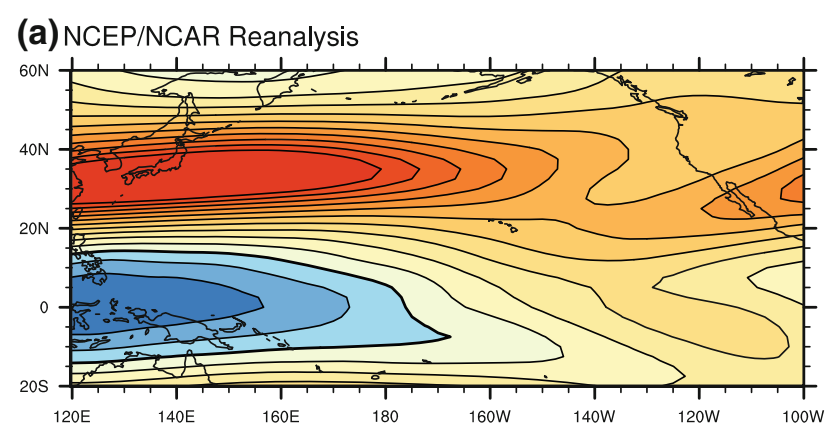

(b) HiGEM1.2

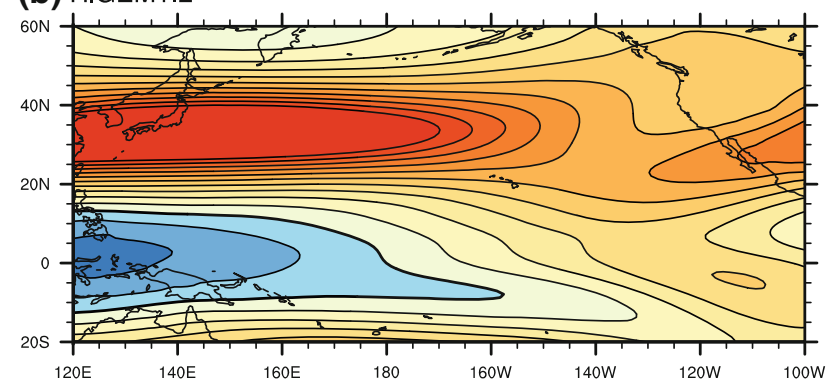

(c) HadGEM1.2

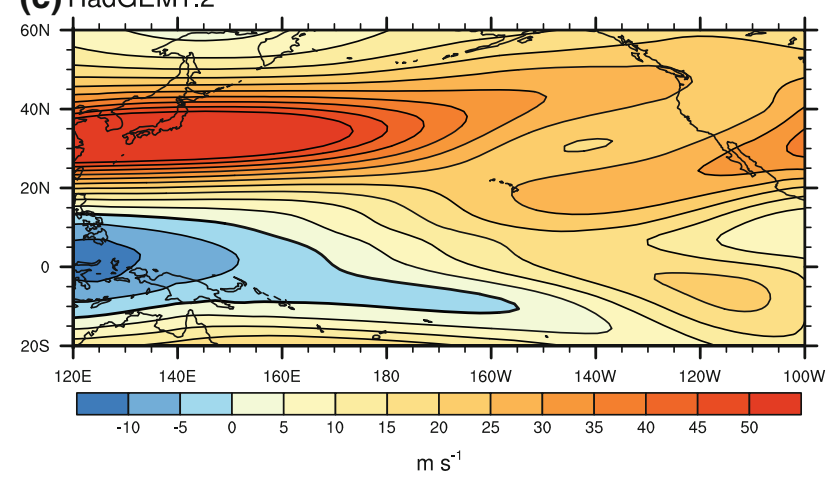

Fig. 750 year time-mean northern winter (NDJFM) zonal wind at $200 \mathrm{hPa}$. Contour interval is $5 \mathrm{~m} \mathrm{~s}^{-1}$, the zero contour is thickened. a NCEP/NCAR reanalysis, b HiGEM1.2, c HadGEM1.2

but with a more elongated taper to the region of mean easterlies in the tropics. However, the basic state in HadGEM1.2 shows significant differences from the observed mean state. In HadGEM1.2, there is a clear separation between the Asian-Pacific and North American jets, with the Asian-Pacific jet continuing into North America, while the North American jet entrance is over Hawaii. The region of mean easterlies in the tropics is also much more tapered and elongated in HadGEM1.2 than in observations.

Although there are clear differences between the mean zonal wind fields from the observations, HiGEM1.2, and HadGEM1.2, the dynamical implications of these differences are not immediately clear. Following Hoskins and Ambrizzi (1993), we use the stationary Rossby wavenumber $\left(K_{s}\right)$ diagnostic to examine the basic state through which Rossby waves propagate. Stationary Rossby wavenumber is a quantity derived entirely from the timemean zonal wind field and is defined as

$K_{s}=\left(\frac{\beta-\bar{u}_{y y}}{\bar{u}}\right)^{\frac{1}{2}}$

where $\bar{u}$ is the time-mean zonal wind, $\beta$ is the meridional planetary vorticity gradient, and $\bar{u}_{y y}$ is the time-mean meridional relative vorticity gradient (the contribution from the meridional wind component has been neglected). It is a highly non-linear diagnostic and is sensitive to small differences in basic state. It may be interpreted as a refractive index for Rossby waves, with waves being refracted toward (away from) latitudes with higher (lower) values of $K_{s}$. We can therefore interpret local maxima in a $K_{s}$ field as Rossby waveguides. We note that refractive index interpretation depends on a scale separation, with the scale of the (Rossby) waves being much smaller than the scale of variations of the atmospheric basic state (Hoskins and Karoly 1981; Karoly 1983; Hoskins and Ambrizzi 1993). Hoskins and Ambrizzi (1993). showed that even though these assumptions may not be strictly valid, the diagnostic and interpretation is still qualitatively useful.

Figure 8 shows zonal stationary Rossby wavenumber over the North Pacific (zonal wavenumber is the number of zonal wavelengths that will fit around a latitude circle). In the observed atmosphere there is a local maximum in $K_{s}$ in the vicinity of the Asian-Pacific jet, extending out over the North Pacific. There is another local maximum in observed $K_{s}$ stretching from the tropical Pacific out over North America. These waveguides, of typical zonal wavenumber 5 , are quite open in structure, almost merging into oneanother in the central North Pacific.

HiGEM1.2 (Fig. 8b) shows more extensive regions of reversed meridional absolute vorticity gradient (dark hatching) where Rossby waves will not propagate, especially over the equatorial Pacific. However, HiGEM1.2 does replicate the rather open waveguide structure of the observations well in the central North Pacific. The waveguides in HiGEM1.2 have typical zonal wavenumber 4-5 and appear to merge somewhat over the central North Pacific.

There are two waveguides over North America: the end of the Pacific jet waveguide at approximately $50^{\circ} \mathrm{N}$, and the entrance to the Atlantic-African jet at $20^{\circ} \mathrm{N}$. In between there is a region of low zonal wavenumber, at approximately $40^{\circ} \mathrm{N}$. In HiGEM1.2 this region of low zonal wavenumber also contains areas of reversed vorticity gradient (Fig. 8b), which do not occur in the observations (Fig. 8a). However, this difference will not be important dynamically, as Rossby waves will still be refracted away from this region in both the HiGEM1.2 and observed basic states. There is a further difference over North America, in 


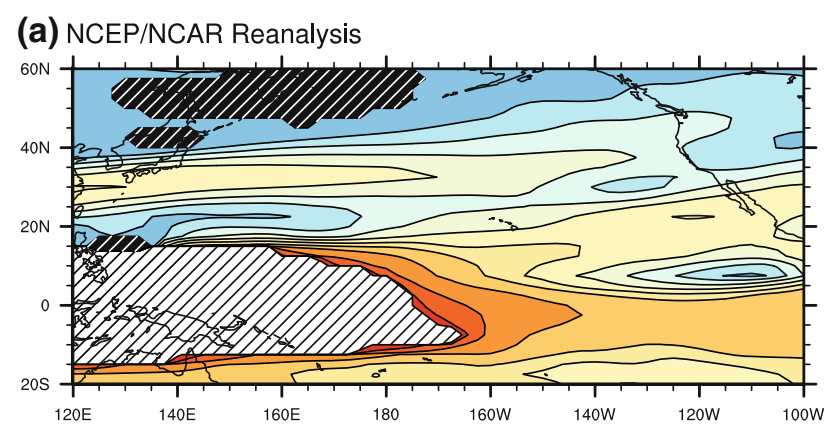

(b) HiGEM1.2

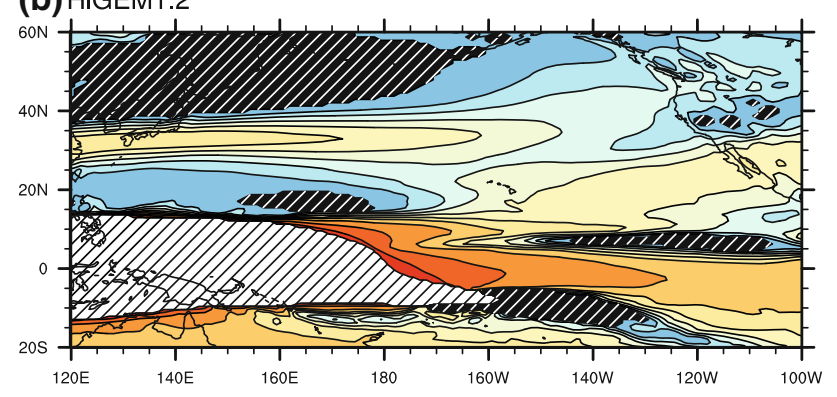

(c) HadGEM1.2

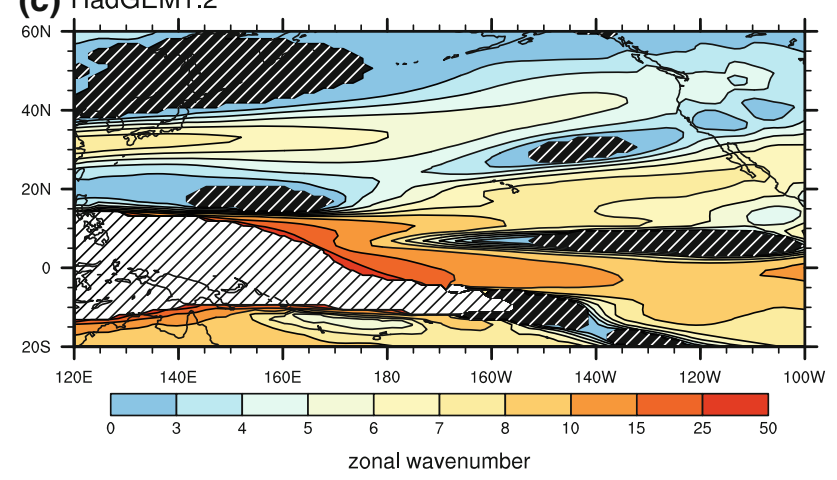

Fig. 8 Zonal stationary wavenumber computed from northern winter (NDJFM) 50 year time-mean zonal wind at $200 \mathrm{hPa}$. Light (dark) hatching indicates areas where $\bar{u}\left(\beta-\bar{u}_{y y}\right)$ is negative. a NCEP/NCAR reanalysis, b HiGEM1.2, c HadGEM1.2

the details of the end of the Pacific jet waveguide at $50^{\circ} \mathrm{N}$. In HiGEM1.2 this has a more broken, noisy structure. These differences are likely to be due to the resolution increase from the $2.5^{\circ} \mathrm{NCEP} / \mathrm{NCAR}$ Reanalysis data to the $1^{\circ}$ HiGEM1.2 atmosphere, allowing for more realistic interactions with topography. The same analysis conducted with the European Centre for Medium Range Weather Forecasting Reanalysis ERA-40 data set (Uppala et al. 2006), which has similar atmospheric horizontal resolution to HiGEM1.2, shows similar structure to HiGEM1.2 over the Rocky Mountains.

HadGEM1.2 shows a rather different waveguide structure in the central North Pacific. The two main waveguides are much more well defined in HadGEM1.2, with each being a separate structure. The two waveguides are divided by an area of reversed meridional absolute vorticity gradient (dark hatching) at $140^{\circ} \mathrm{W} 30^{\circ} \mathrm{N}$, which will strongly repel Rossby waves and across which they will not propagate.

As an example, consider Rossby waves of zonal wavenumber 4-5 propagating in the observed atmosphere. This wavenumber is chosen because it corresponds approximately to the wavenumber of the Northern Hemisphere wave train produced as a response to El Niño forcing (Fig. 3). These waves are likely to be partially refracted into the tropical Pacific waveguide when they reach the end of the Asian-Pacific jet waveguide due to the close proximity of the two waveguides. This would also be true of Rossby waves in the HiGEM1.2 atmosphere. However, in the HadGEM1.2 atmosphere this is less likely due to the relative separation of the two waveguides and the area of reversed meridional absolute vorticity gradient blocking the refraction of Rossby waves into the tropical waveguide.

This subtle, yet dynamically significant feature of the HadGEM1.2 atmospheric mean state could potentially send Rossby waves along very different propagation paths, and hence induce very different circulation anomalies than exist in the observed atmosphere.

\section{Rossby wave generation}

Analysis of the atmospheric background state showed that, once generated, Rossby waves in HadGEM1.2 are likely to propagate differently to those in the observed atmosphere, leading to a different extra-tropical response to El Niño. Another possible factor could be a difference in the generation of these Rossby waves. Tropical convection and atmospheric heating due to anomalous SSTs has a major role in the generation of atmospheric planetary scale waves (Hoskins and Karoly 1981). The vertical convective motion leads to convergence at the surface and divergence in the upper troposphere, which induces an anomalous upper level vorticity source, referred to as the Rossby wave source (RWS); (Sardeshmukh and Hoskins 1988). It is the RWS that forces the Rossby wave train that forms a large component of the El Niño teleconnection signal in the extra-tropical atmosphere. The RWS can give a more insightful view of the forcing mechanisms producing Rossby waves than is possible to gain from examining surface forcing alone as in Fig. 2.

Sardeshmukh and Hoskins (1988) define Rossby wave source, $S$, as

$S=-\left(\zeta \nabla \cdot \mathbf{v}_{\chi}+\mathbf{v}_{\chi} \cdot \nabla \zeta\right)$,

where $\zeta$ is absolute vorticity, and $\mathbf{v}_{\chi}$ is the divergent (irrotational) component of wind.

Regression maps of the RWS anomaly associated with El Niño for observations, HiGEM1.2, and HadGEM1.2 are 


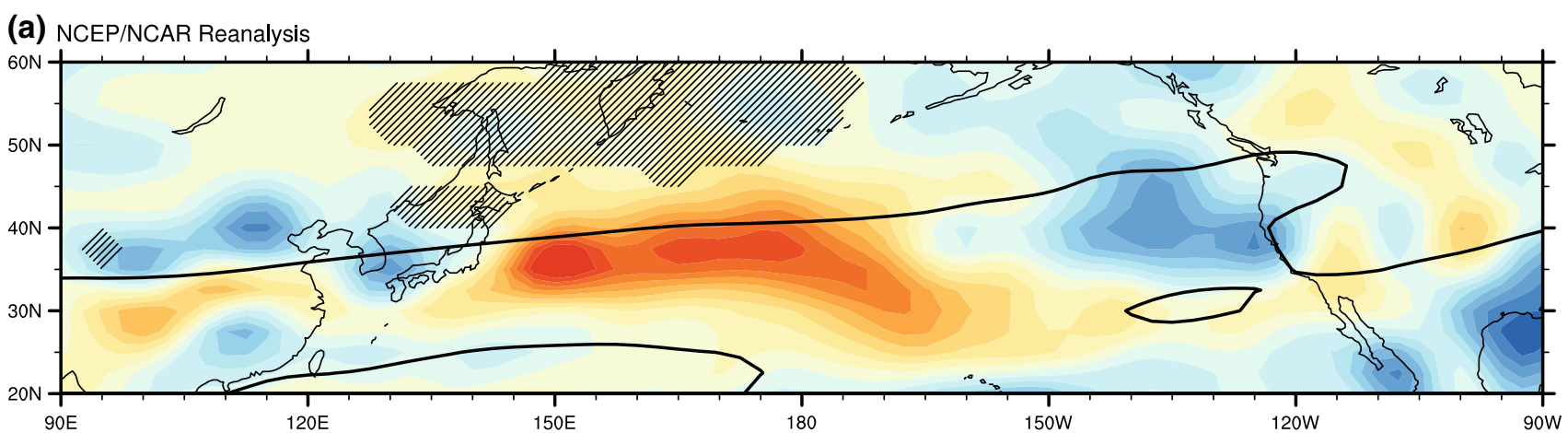

(b) HiGEM1.2

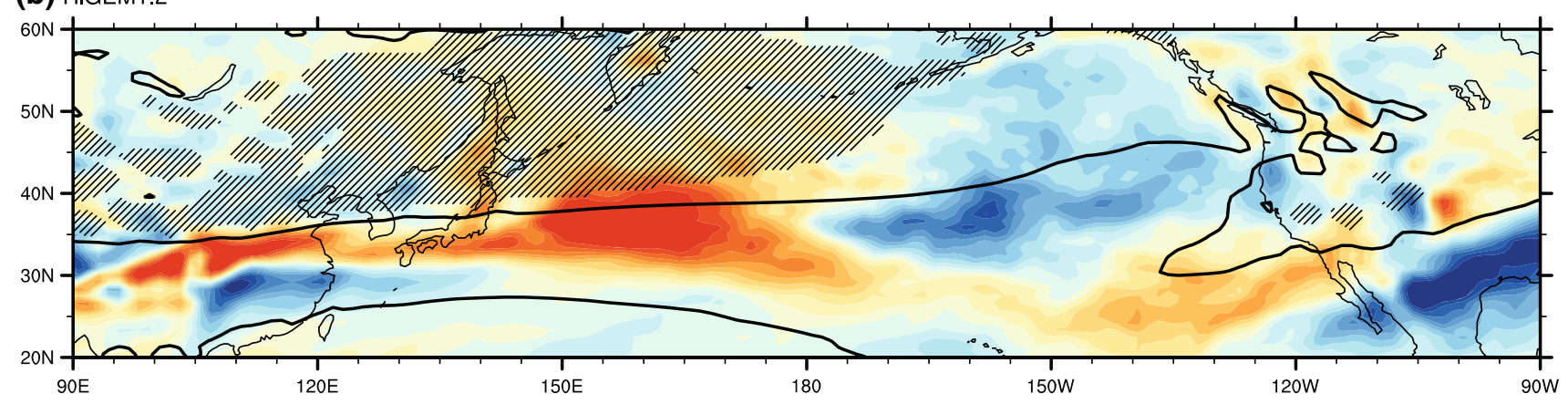

(c) HadGEM1.2

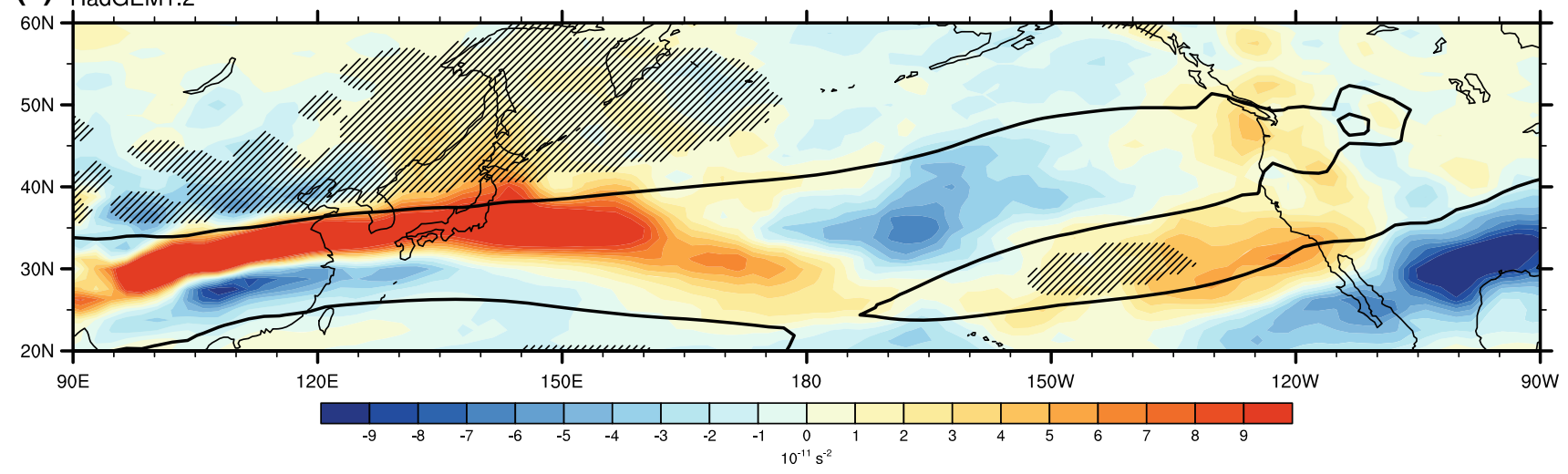

Fig. 9 Regression maps of Rossby wave source anomaly associated with a $1^{\circ}$ departure of the EP index. Contour interval is $10^{-11} \mathrm{~s}^{-2}$. The thick contour is stationary wavenumber $K_{s}=4$. Hatching as in Fig. 8. a NCEP/NCAR reanalysis, b HiGEM1.2, c HadGEM1.2

shown in Fig. 9. In order to understand RWS in the context of anomalous Rossby wave response to El Niño, the contour of stationary zonal wavenumber $K_{s}=4$ is overlaid on RWS in Fig. 9. The wave train seen in Fig. 3 has a zonal wavenumber of approximately $4-5$. Since these are not pure harmonic plane waves it is reasonable to choose the waveguide of zonal wavenumber 4 as an approximation to the propagation paths of these waves. Regions of reversed absolute vorticity gradient are hatched as in Fig. 8.

In the observations there is a positive RWS anomaly associated with El Niño in the North-West Pacific. This generates the cyclonic (positive vorticity) anomaly over the extra-tropical North Pacific seen in Fig. 3a (cyclonic, negative stream function anomaly). This RWS anomaly is strong, and also is spread over a large area. This implies significant generation of Rossby waves both inside and outside of the $K_{s} \geq 4$ waveguide. Waves of zonal wavenumber 4 or higher generated inside the waveguide will tend to follow it, and likely exit in the vicinity of the central Pacific waveguide, possibly entering it and following it across North America. Waves generated outside the Asian-Pacific jet waveguide may follow other trajectories.

A similar situation is seen in HiGEM1.2. Although the RWS anomaly is a different shape and has a greater westerly extent, being present in the Asian jet over land, the 
wave generation in HiGEM1.2 is active both inside and outside the $K_{s} \geq 4$ waveguide, suggesting similar wave propagation mechanisms are operating to those in the observations. However, in HadGEM1.2 the RWS is elongated and constrained more tightly into the jet. As a consequence of this, most wave generation is inside the $K_{s} \geq 4$ waveguide. This implies that most of the waves generated there will be trapped inside the Asian-Pacific jet waveguide. Unlike the observations or HiGEM1.2, the waveguide in HadGEM1.2 does not exit in the vicinity of the central Pacific waveguide, instead it remains distinct and is oriented more to the northeast. However, it is clear that the RWS in HiGEM1.2 and HadGEM1.2 are more similar to one another than they are to the RWS in observations. Hence, even though there are differences between the RWS anomaly patterns in HiGEM1.2 and HadGEM1.2, this suggests that these differences in the generation of Rossby waves are less significant than the influence of the atmosphere background state on the preferred propagation paths of Rossby waves, in determining the extra-tropical response to El Niño.

\section{Conclusions}

The global simulation of El Niño in a low resolution GCM (HadGEM1.2) typical of the models used in the AR4 climate change assessment is compared with the simulation in a higher resolution version of the same model (HiGEM1.2) and observations. The spatial distribution of tropical SST anomaly during El Niño is simulated well by both HiGEM1.2 and HadGEM1.2. It is in the extra-tropical SST response where the high and low resolution models differ greatly. HiGEM1.2 is capable of reproducing the large scale cold anomaly in the central North Pacific associated with El Niño as seen in observations. It also produces a warm anomaly along the Pacific coast of North America. HadGEM1.2 on the other hand, simulates the North Pacific SST response very poorly, only managing a small portion of the cold anomaly that should exist in the central North Pacific, and no significant warm anomaly along the Pacific coast of North America.

An analysis of tropical convective forcing showed similar patterns of convection in HiGEM1.2 and HadGEM1.2. Although there are small differences between the high and low resolution models, this suggests that there is more to the incorrect North Pacific SST response than simply inadequate surface forcing for the atmospheric bridge. The anomaly response in the upper troposphere of HadGEM1.2 is very different to observations, whereas HiGEM1.2 showed similar circulation anomalies to those seen in the reanalysis data set. This suggests that upper tropospheric wave anomalies are being excited and propagated in an unrealistic manner in HadGEM1.2.

The extra-tropical SST response to El Niño in HiGEM1.2 and HadGEM1.2 can be explained by the anomalous surface circulation that is induced by the uppertropospheric circulation anomalies. The majority of the extra-tropical SST response is explained by altered surface sensible and latent heat fluxes caused by changes in total wind speed, consistent with previous studies (e.g., Luksch and von Storch 1992; Deser and Blackmon 1995). The direction of the surface circulation anomalies also has an important role. The advection of warmer, more humid air over the North American coastal region is a key factor in HiGEM1.2 producing an accurate response there. The direction of the anomalous circulation in this region is also important for upwelling. In HiGEM1.2 these winds act to suppress upwelling, but in HadGEM1.2 they are favourable to upwelling. Hence, HiGEM1.2 has a more realistic extratropical SST response as it simulates the large scale upper tropospheric response to El Niño well, and hence the surface circulation anomalies in the extra-tropics. HadGEM1.2 has a different upper level response and does not produce the surface circulation anomalies required in order to produce a realistic extra-tropical SST response.

The mechanisms giving rise to the extra-tropical circulation anomalies were explored through analysis of the dynamics of the atmospheric basic state, the medium through which Rossby waves propagate. Seemingly subtle differences in the time-mean zonal wind fields between HadGEM1.2 and the observed atmosphere were shown to have significant dynamical consequences. HadGEM1.2 tends to propagate waves out of the Asian-Pacific jet in a more constrained manner, sending them north of a position that would allow them to freely enter the waveguide associated with the North American Jet. A critical area of reversed absolute vorticity gradient, through which Rossby waves will not propagate, reinforced the separation of the two waveguides. HiGEM1.2 had a very similar Pacific regional waveguide structure to the observed atmosphere.

The Rossby wave source diagnostic was used to analyse Rossby wave generation. Rossby wave source was found to be similar between HiGEM1.2 and HadGEM1.2 over the North Pacific region. The RWS anomaly in HadGEM1.2 is more elongated and constrained more tightly into the Asian-Pacific jet waveguide than in HiGEM1.2. However, it seems that differences in RWS anomaly are less important than the differences in preferred Rossby wave propagation paths. Given the large differences in waveguide structure, and the smaller differences in Rossby wave generation, it would be unreasonable to expect HadGEM1.2 to simulate the extra-tropical SST response to El Niño correctly. 
Whilst we have shown that differences in Rossby wave propagation can explain the differences in extra-tropical response to El Niño in high and low resolution coupled models, it is possible that there are processes that we have not discussed that make some contribution. Hurrell et al. (2006) showed that increasing horizontal resolution, along with some minor changes to model physics, in an atmosphere model improved the position and strength of midlatitude storm tracks. An improved representation of storm tracks could lead to more accurate feedback of baroclinic eddies on to the mean state, thus altering Rossby wave propagation paths. The idealised study of Franzke et al. (2000) suggests that baroclinic eddies in the storm track can directly interact with Rossby waves, modulating their amplitude. This would provide an extra influence on Rossby wave propagation in addition to the basic state. Since the physics of the extra-tropical response to El Niño are explained well by differences in the basic state, this type of direct interaction is likely to be a process of secondary importance.

The atmospheric response to tropical SST anomalies is a complicated and interconnected system. Here we have studied a major subcomponent of this system. We considered the effect of tropical SST anomalies on the tropical and extra-tropical atmosphere, and how these atmospheric anomalies produce extra-tropical SST anomalies. Further processes then occur that we have not discussed in this work. The extra-tropical SST anomalies themselves will induce extra-tropical atmospheric circulation anomalies. These anomalies are typically modest in comparison with internal atmospheric variability (Kushnir et al. 2002). Peng and Robinson (2001) showed that the atmospheric response to an extra-tropical SST anomaly is strongly dependent on transient eddies, and that the response projects strongly onto patterns of atmospheric internal variability. As discussed in Kushnir et al. (2002), we can use a simple linear scaling of the atmospheric response presented by Peng and Robinson to an SST anomaly comparable to that produced in the extra-tropical response to El Niño, to show that the magnitude of the atmospheric response to an extra-tropical SST anomaly is around an order of magnitude smaller than that induced by El Niño SST anomalies. This suggests that the atmospheric response to El Niño SST anomalies dominates over secondary atmospheric feedback from extra-tropical SST anomalies.

The resolution of HadGEM1.2 is typical of the climate forecast models used in the IPCC fourth assessment report (Randall et al. 2007). Climate forecast models need to be able to simulate El Niño and the extra-tropical SST response when used for climate change experiments. This is because the behaviour of other parts of the climate system (e.g., monsoons, tropical cyclones, mid-latitude storm tracks) are closely linked to El Niño and its extra- tropical SST response. Here we have shown that a improved simulation of the mean state in a relatively high resolution model has led to an improvement in this aspect of the variability.

Acknowledgments NCEP/NCAR reanalysis data were provided by the NOAA/OAR/ERSL PSD, Boulder Colorado, USA, from their web site at http://www.cdc.noaa.gov/. The UKMO HadISST data were provided by the British Atmospheric Data Centre, from their website at http://badc.nerc.ac.uk/data/hadisst/. AD was supported by a NERC $\mathrm{PhD}$ studentship. The support of NERC through the UK HiGEM project is acknowledged. We thank two anonymous reviewers whose comments helped to improve the manuscript.

\section{References}

AchutaRao K, Sperber K (2002) Simulation of the El Niño southern oscillation: results from the coupled model intercomparison project. Clim Dyn 19(3):191-209

Alexander MA (1992) Midlatitude atmosphere-ocean interaction during El Niño. Part II: The northern hemisphere atmosphere. J Clim 5(9):959-972

Alexander MA, Bladé I, Newman M, Lanzante JR, Lau NC, Scott JD (2002) The atmospheric bridge: the influence of ENSO teleconnections on air-sea interaction over the global oceans. J Clim 15(16):2205-2231

Brayshaw D, Hoskins B, Blackburn M (2008) The storm-track response to idealized SST perturbations in an aquaplanet GCM. J Atmos Sci 65(9):2842-2860

Deser C, Blackmon ML (1995) On the relationship between tropical and North Pacific sea surface temperature variations. J Clim 8(6): $1677-1680$

Franzke C, Fraedrich K, Lunkeit F (2000) Low-frequency variability in a simplified atmospheric global circulation model: Stormtrack induced 'spatial resonance'. Q J Roy Meteorol Soc 126(569):2691-2708

Gordon C, Cooper C, Senior CA, Banks H, Gregory JM, Johns TC, Mitchell JFB, Wood RA (2000) The simulation of SST, sea ice extents and ocean heat transports in a version of the Hadley Centre coupled model without flux adjustments. Clim Dyn 16(2):147-168

Guilyardi E, Gualdi S, Slingo J, Navarra A, Delecluse P, Cole J, Madec G, Roberts M, Latif M, Terray L (2004) Representing El Niño in coupled ocean-atmosphere GCMs: the dominant role of the atmospheric component. J Clim 17(24):4623-4629

Hoskins BJ, Ambrizzi T (1993) Rossby wave propagation on a realistic longitudinally varying flow. J Atmos Sci 50(12):16611671

Hoskins BJ, Karoly DJ (1981) The steady linear response of a spherical atmosphere to thermal and orographic forcing. J Atmos Sci 38(6):1179-1196

Hoskins BJ, McIntyre ME, Robertson AW (1985) On the use and significance of isentropic potential vorticity maps. Q J Roy Meteorol Soc 111(470):877-946

Hurrell JW, Hack JJ, Phillips AS, Caron J, Yin J (2006) The dynamical simulation of the community atmosphere model version 3 (CAM3). J Clim 19(11):2162-2183

Inatsu M, Mukougawa H, Xie S (2002) Tropical and extratropical SST effects on the midlatitude storm track. J Meteorol Soc Jpn 80(4B):1069-1076

Johns TC, Durman CF, Banks HT, Roberts MJ, McLaren AJ, Ridley JK, Senior CA, Williams KD, Jones A, Rickard GJ, Cusack S, Ingram WJ, Crucifix M, Sexton DMH, Joshi MM, Dong BW, 
Spencer H, Hill RSR, Gregory JM, Keen AB, Pardaens AK, Lowe JA, Bodas-Salcedo A, Stark S, Searl Y (2006) The new Hadley Centre climate model (HadGEM1): evaluation of coupled simulations. J Clim 19(7):1327-1353

Kalnay E, Kanamitsu M, Kistler R, Collins W, Deaven D, Gandin L, Iredell $\mathrm{M}$, Saha $\mathrm{S}$, White $\mathrm{G}$, Woolen J, Zhu Y, Leetmaa A, Reynolds B, Chelliah M, Ebisuazaki W, Higgins W, Jonowiak J, Mo KC, Ropelewski C, Wang J, Jenne R, Joseph D (1996) The NCEP/NCAR 40-year reanalysis project. Bull Am Meteorol Soc 77(3):437-471

Karoly D (1983) Rossby wave propagation in a barotropic atmosphere. Dyn Atmos Oceans 7(2):111-125

Kiladis GN, Weickmann KM (1992) Circulation anomalies associated with tropical convection during northern winter. Mon Weather Rev 120(9):1900-1923

Kushnir Y, Robinson WA, Bladé I, Hall NMJ, Peng S, Sutton R (2002) Atmospheric GCM response to extratropical SST anomalies: synthesis and evaluation. J Clim 15(16):2233-2256

Luksch U, von Storch H (1992) Modelling the low-frequency sea surface temperature variability in the North Pacific. J Clim 5(9):893-906

Mechoso CR, Robertson AW, Barth N, Davey MK, Delecluse P, Gent PR, Ineson S, Kirtman B, Latif M, Treut HL, Nagai T, Neelin JD, Philander SGH, Polcher J, Schopf PS, Stockdale T, Suarez MJ, Terray L, Thual O, Tribbia JJ (1995) The seasonal cycle over the tropical Pacific in coupled ocean-atmosphere general circulation models. Mon Weather Rev 123(9):2825-2838

Navarra A, Gualdi SSM, Behera S, Luo JJ, Masson S, Guilyardi E, Delecluse P, Yamagata T (2008) Atmospheric horizontal resolution affects tropical climate variability in coupled models. J Clim 21(4):730-750

Norris JR (2000) Interannual and interdecadal variability in the storm track, cloudiness, and sea surface temperature over the summertime North Pacific. J Clim 13(2):422-430

Peng S, Robinson WA (2001) Relationships between atmospheric internal variability and and the responses to an extratropical SST anomaly. J Clim 14(13):2943-2959

Philander SG (1990) El Niño, La Niña, and the southern oscillation, 1 st edn. Academic Press, London

Pope V, Stratton R (2002) The processes governing horizontal resolution sensitivity in a climate model. Clim Dyn 19(3):211236

Randall DA, Wood RA, Bony S, Colman R, Fichefet T, Fyfe J, Kattsov V, Pitman A, Shukla J, Srinivasan J, Stouffer RJ, Sumi A, Taylor KE (2007) Climate Change 2007: the physical science basis. Contribution of working group I to the fourth assessment report of the intergovernmental panel on climate change. In: Solomon S, Qin D,Manning M, Chen Z, Marquis M, Averyt KB, Tignor M, Miller HL (eds) Cambridge University Press, Cambridge, United Kingdom and New York, NY, USA, Chap climate models and their evaluation

Rayner NA, Parker DE, Horton EB, Folland CK, Alexander LV, Rowell DP, Kent EC, Kaplan A (2003) Global analyses of sea surface temperature, sea ice, and night marine air temperature since the late nineteenth century. J Geophys Res 108(D14):4407

Roberts MJ, Banks H, Gedney N, Gregory J, Hill R, Mullerworth S, Pardaens A, Rickard G, Thorpe R, Wood R (2004) Impact of an eddy-permitting ocean resolution on control and climate change simulations with a global coupled GCM. J Clim 17(1):3-20

Roberts MJ, Clayton A, Demory ME, Donners J, Vidale PL, Norton W, Shaffrey L, Stevens DP, Stevens I, Wood RA, Slingo J (2009) Impact of resolution on the tropical pacific circulation in a matrix of coupled models. J Clim 22(10):2541-2556

Sardeshmukh PD, Hoskins BJ (1988) The generation of global rotational flow by steady idealized tropical divergence. J Atmos Sci 45(7):1228-1251

Shaffrey LC, Stevens I, Norton WA, Roberts MJ, Vidale PL, Harle JD, Jrrar A, Stevens DP, Woodage MJ, Demory ME, Donners JBCD, Clayton A, Cole JW, Wilson SS, Connolley WM, Davies TM, Iwi AM, Johns TC, King JC, New AL, Slingo JM, Slingo A, Steenman-Clark L, Martin GM (2009) UK-HiGEM: the new UK high resolution global environment model. Model description and basic evaluation. J Clim 22(8):1861-1896

Trenberth KE (1997) The definition of El Niño. Bull Am Meteorol Soc 78(12):2771-2777

Uppala SM, Kållberg PW, Simmons AJ, Andrae U, Da CostaBechtold V, Fiorino M, Gibson JK, Haseler J, Hernandez A, Kelly GA, Li X, Onogi K, Saarinen S, Sokka N, Allan RP, Andersson E, Arpe K, Balmaseda MA, Beljaars ACM, Van De Berg L, Bidlot J, Bormann N, Caires S, Chevallier F, Dethof A, Dragosavac M, Fisher M, Fuentes S, Hagemann M, Hólm E, Hoskins BJ, Isaken L, Janssen PAEM, Jenne R, McNally AP, Mahfouf JF, Morcrette JJ, Rayner NA, Saunders RW, Simon P, Sterl A, Trenberth KE, Untch A, Vasiljevic D, Viterbo P, Woollen J (2006) The ERA-40 reanalysis. Q J Roy Meteorol Soc 131(612):2961-3012

Wilks DS (2006) Statistical analysis in the atmospheric sciences, 2nd edn. Academic Press, London 